\title{
Nature-Based Solutions and Sustainable Urban Planning in the European Environmental Policy Framework: Analysis of the State of the Art and Recommendations for Future Development
}

\author{
Claudia de Luca ${ }^{1, *} \mathbb{0}$, Sandra Naumann ${ }^{2}$, McKenna Davis ${ }^{2}$ and Simona Tondelli ${ }^{1}(\mathbb{C}$ \\ 1 Alma Mater Studiorum, Department of Architecture, University of Bologna, 40136 Bologna, Italy; \\ simona.tondelli@unibo.it \\ 2 Ecologic Institute, 10717 Berlin, Germany; sandra.naumann@ecologic.eu (S.N.); \\ mckenna.davis@ecologic.eu (M.D.) \\ * Correspondence: claudia.deluca5@unibo.it
}

Citation: de Luca, C.; Naumann, S.; Davis, M.; Tondelli, S. Nature-Based Solutions and Sustainable Urban Planning in the European Environmental Policy Framework: Analysis of the State of the Art and Recommendations for Future Development. Sustainability 2021, 13, 5021. https://doi.org/10.3390/ su13095021

Academic Editors: Paola Di Biagi, Sara Basso and Alessandra Marin

Received: 30 March 2021

Accepted: 26 April 2021

Published: 29 April 2021

Publisher's Note: MDPI stays neutral with regard to jurisdictional claims in published maps and institutional affiliations.

Copyright: (c) 2021 by the authors. Licensee MDPI, Basel, Switzerland. This article is an open access article distributed under the terms and conditions of the Creative Commons Attribution (CC BY) license (https:// creativecommons.org/licenses/by/ $4.0 /)$.

\begin{abstract}
Sustainable urban planning (SUP) is crucial in the development of sustainable cities, as also underlined by the New Urban Agenda. Nature-based solutions (NBS) are increasingly being recognized for their potential to offer multiple benefits that are necessary in order to cope with present and future urban challenges. The European policy framework, including the recently released European Green Deal, could strongly boost the role and recognition of NBS and SUP as drivers of sustainable and inclusive urban transition. Through a content analysis of current environmental European policies, strategies and agreements, this paper provides (i) an overview of the state of the art of the environmental European policy framework and the recognized role of NBS and SUP in reaching defined objectives, and (ii) insights on where NBS and SUP could play a larger role within this framework. On this basis, the paper identifies gaps and develops recommendations for a better integration of such concepts into the current framework.
\end{abstract}

Keywords: sustainable urban planning; nature-based solutions; European policy framework

\section{Introduction}

A trend of ongoing economic growth over the last two centuries has largely resulted in higher living standards and improved quality of life for the European population. Nevertheless, this process has also highlighted disparities among people [1] and has resulted in an increasing depletion of natural resources, degradation of ecosystems [2] and changes in the atmosphere, resulting in climate change and climate fluctuations [3]. At the same time, a critical interlinkage exists, in which natural resources are vital for securing economic growth and development and are at the same time threated by the very economic system they support [4].

The impact of humans on the natural world has a long history. Scientists place the start of the so-called Anthropocene [5] from the second half of the nineteenth century, i.e., the period in which human activity dominates the development of global ecosystems [6]. This concept introduces the idea that the human species has become a geological force in terms of its capacity to impact Earth's processes [7]. Concretely, humans have pushed the planet to overcome its natural carrying capacity in terms of resource provisioning [8,9]; depleted the health, regenerative capacity and functions of its ecosystems; and affected its natural cycles and functioning.

Europe's urban areas are home to over two-thirds of the EU's population, yet account for about $80 \%$ of energy use and generate up to $85 \%$ of Europe's GDP [10]. These areas serve as a fertile ground for innovation, hosting knowledge hubs which are nurtured by different stakeholders, such as universities, local authorities, citizen associations, NGOs and private enterprises. At the same time, urban areas are also home to persistent problems, 
including unemployment, segregation and poverty. Social and health-related challenges are common to urban areas, as well as ecological and environmental issues.

Nature-based solutions (NBSs) are becoming increasingly recognized as solutions that can offer multiple benefits necessary to cope with these and future urban challenges [11-13]. By utilizing the properties of natural systems, NBS can provide a wide range of ecosystem services (ES), such as microclimate regulation, runoff control, as well as opportunities for mental and physical recreation, and can thereby benefit citizen health and wellbeing $[13,14]$.

Urban policies and strategies can play a central role in boosting NBS implementation, thereby maintaining and increasing ES to foster more sustainable, livable and resilient cities [15]. Sustainable urban planning (SUP) is crucial in the development of sustainable cities and in the overall transition towards more sustainable societies, as also underlined by the New Urban Agenda [16]. Accordingly, the European policy framework and its recently released European Green Deal could strongly boost the role and the recognition of NBS and SUP as powerful drivers of a sustainable and inclusive urban transition.

European environmental policies can be traced back to the original European Economic Community Treaty [17]. Although the treaty did not contain explicit references to EU competences on environmental issues, it did refer to raising the standard of living and improving the working conditions of people in line with the rights developed within the Human Rights Declaration of 1948 [18]. In the late 1960s, Europe and the international community could no longer overlook increasing public concern for the environment. Following the 1972 Stockholm Declaration [19], the European heads of state and government decided at the European Council in Paris to establish the first environmental action program, marking the official beginning of a European environmental policy [20]. Since then, the EU's environmental policy has developed into a comprehensive and complex regime. Through article 130 (now article 192-193) of the Treaty on the Functioning of the European Union, the council was granted specific competencies over environmental policy. The European Commission then started in the 1990s to act as a supranational institution, representing the EU in international environmental treaty negotiations, including the promotion of its own policy models at the international level [20].

This paper provides an overview of the role of NBS and SUP in securing a sustainable and inclusive urban transition, looking at relevant European environmental directives, strategies and agreements. Through a content analysis of the current environmental European policy framework, this paper provides: (i) an overview of the state of the art of the current environmental European policy framework and the recognized role of NBS and SUP in reaching defined objectives, and (ii) insights on where NBS and SUP could play a larger role within this framework. On this basis, the paper identifies gaps and develops recommendation for a better integration of such concepts into the current framework.

\section{Conceptual Approach and Methodology}

In the scope of our analysis, 'policies' refer both to binding legislation (e.g., directives, regulations and decisions) and non-binding strategies and programs (e.g., strategies, action plans and programs) [21]. To define the current environmental European policy framework, we have followed the sectorial division of the EU Commission within the DG for the Environment, clustering EU policies into the following sectors:

- Environment as an overarching issue

- Biodiversity

- Climate Change

- Water

- Coastal areas and marine environment

- Circular economy

- Environmental impact

- Public procurement

For each sector, all relevant policies were analyzed to verify and assess the relevance and the role of NBS and SUP. A short summary was developed for the different sectors and 
each policy, summarizing the aim and links to NBS and SUP. Consistent with [22,23], the policy screening did not employ a strict keyword-based content analysis, but rather relied on both explicit and non-explicit qualitative content analysis. In particular, determination of the role of NBS also considered references to green infrastructure, ecosystem-based approaches and natural water retention measures, due to the fact that the term has only recent been adopted by the European Commission [24]. More specifically, the policies were reviewed for:

1. General or specific references to the role of NBS (and related terms) in the achievement of defined targets, and potential roles not recognized by the policy but potentially relevant

2. General or specific reference to SUP and its role in the achievement of defined targets, and potential roles not recognized by the policy but potentially relevant

The authors contributed expert judgement on two diverse issues, namely, on (1) the level of integration of NBS and SUP in the analyzed policies to reach the defined target and (2) the potential relevance of NBS and SUP to reach the defined target. These qualitative judgements were expressed according to pre-defined criteria, which were agreed upon by the authors; these are detailed in Table 1 below. In the case of differing opinions, open discussions were conducted among authors to reach consensus for the final judgement.

Table 1. Expert judgement and qualitative criteria used.

\begin{tabular}{|c|c|c|}
\hline Expert Judgement & $\begin{array}{c}\text { Integration of NBS and SUP in } \\
\text { the Analyzed Policies to Reach } \\
\text { the Defined Target }\end{array}$ & $\begin{array}{l}\text { Potential Relevance of NBS and } \\
\text { SUP to Reach the Defined Target }\end{array}$ \\
\hline High (5) & $\begin{array}{l}\text { Role of NBS (or synonyms) and } \\
\text { SUP is explicitly mentioned and } \\
\text { addressed in good detail in the } \\
\text { policy document. Clear statement } \\
\text { and integration of NBS and SUP in } \\
\text { the achievement of policy objectives } \\
\text { and targets. }\end{array}$ & $\begin{array}{l}\text { NBS and SUP can play a very } \\
\text { relevant role in reaching the policy } \\
\text { objectives and targets, according to } \\
\text { the expert knowledge } \\
\text { and judgement. }\end{array}$ \\
\hline Medium (3) & $\begin{array}{l}\text { Some elements of the potential role } \\
\text { of NBS and SUP are included and } \\
\text { addressed, but no detailed reference } \\
\text { to their integration into related } \\
\text { policy targets and objectives. }\end{array}$ & $\begin{array}{c}\text { NBS and SUP can play some role } \\
\text { in reaching the policy objectives } \\
\text { and targets. }\end{array}$ \\
\hline Low (1) & $\begin{array}{l}\text { Few or no elements of the potential } \\
\text { role of NBS and SUP are included } \\
\text { and addressed and no reference of } \\
\text { their integration into related policy } \\
\text { targets and objectives. }\end{array}$ & $\begin{array}{l}\text { NBS and SUP are not considered } \\
\text { relevant in reaching the policy } \\
\text { objectives and targets, according to } \\
\text { the expert knowledge } \\
\text { and judgement. }\end{array}$ \\
\hline
\end{tabular}

To highlight gaps between the recognized role of NBS and SUP and their potential in reaching policy targets and objectives, the qualitative judgments were translated into a quantitative assessment, translating the qualitative scale of the interval used for the assessment (low, medium and high) into a quantitative scale (1, 3 and 5). To facilitate the final representation of the results and highlight gaps, the scores given to the recognized roles of NBS and SUP were subtracted from the scores given to the potential relevance of NBS and SUP.

Although it is beyond the scope of this paper, it should nevertheless be recognized that the degree and effectiveness of implementation of the analyzed policies in the Member States plays a crucial role in the actual impact NBS and SUB can have on the ground.

\section{Results}

This section first presents the results of the policy review, summarizing the diverse findings per sector (Section 3.1). On this basis, the results have been elaborated, analyzing 
the various gaps and suggesting the fields where actions should be taken most urgently (Section 3.2).

\subsection{Sectorial Analysis of NBS and SUP Integration into the EU Environmental Policy Framework}

3.1.1. Environment as an Overarching Issue, the Environmental Action Program and the European Green Deal

The first EU Environmental Action Program (EAP) was developed and approved in 1972, defining thematic priorities and objectives for the following seven years. Since then, the European Union has developed seven EAPs and is now in the process of developing an 8th program that will run from 2021 to 2028.

In the 7th EAP, running from 2013 to 2020 [25], the importance of cities' transitions towards sustainability is not well highlighted or recognized, despite citizens' health and wellbeing being included as one of the thematic priorities. The role of nature in reaching the thematic priorities is clearly recognized, mostly linked to habitat preservation and connections and to climate change mitigation and adaptation. Nevertheless, protecting and conserving European biodiversity and nature remains the most discouraging area, in terms of progress that has been made to date [26]. Of the 13 specific policy objectives set in this area to be reached by 2020, only two are likely be met: the designation of marine and terrestrial protected areas. According to the European environment-state and outlook 2020 report [26], European environment and climate policies have helped to improve the environment over recent decades, but Europe is not making enough progress. Since the new European Commission assembled in 2019, environmental issues and challenges have been placed as a top priority. The 8th EAP is currently under development, but the first communication from the European Council [27] clearly states the crucial role of ecosystems and of their service as a foundation of a fair, healthy and prosperous society.

At the same time, the European Commission is now developing an ambitious program that puts sustainable and just development at the center of European growth towards 2050. This European Green Deal represents the main new ambition of the European Commission and outlines a strategy for Europe to become the world's first climate-neutral continent by 2050 [28]. What is crucial to notice in the deal is that environment is now at the center of all other sectors, such as economy, development, energy and justice. Currently available documents that have been individually analyzed in the different sectors provide the basis for a comprehensive policy framework, encompassing the climate, energy, environmental, industrial, economic and social aspects of this unprecedented process [29].

\subsubsection{Biodiversity}

The recognition of the role of biodiversity and ecosystem health in EU policies started in 1979 with the development of the Birds Directive, aiming to protect wild bird species and their habitats. Together with the passing of the Habitat Directive in 1992, these directives created the legislative base and identified the most valuable and threatened species and habitats for the development of the Natura 2000 network [30]. Made up of sites designated under the Birds and Habitats Directives, the Natura 2000 network is the largest coordinated network of protected areas in the world. It is comprised of core breeding and resting sites for rare and threatened species and some rare natural habitat types, which are protected in their own right, and stretches across all $27 \mathrm{EU}$ countries. It currently covers around $18 \%$ of the EU's terrestrial area and $6 \%$ of its marine territory [31]. The connectivity of protected areas, such as the Natura 2000 network, is crucial for maintaining healthy ecosystems and for the delivery of ecosystem services into the wider landscapes and urban areas in which they are embedded. Ecosystem fragmentation is considered one of the main threats to ecosystem health and threatens the resilient provisioning of critical ecosystem services [31].

The Natura 2000 sites represent the backbone of the European green infrastructure network. As previously mentioned, green infrastructure (GI) is a strategically planned network of natural and semi-natural areas that provides multiple benefits to humans and the environment [32]. The protection, maintenance and improvement of green infrastructure 
can ensure multiple benefits at various scales, supporting biodiversity and environmental targets, as well as socio-economic objectives. The definition of what comprises the European green infrastructure network is not a simple biodiversity and habitat-related topic, as outlined in the Habitat and the Birds Directives, but rather a wider political issue that needs to be tackled at the appropriate political scale. For this reason, the European Commission released its Green Infrastructure Strategy in 2013, recommending a better integration of GI and the contributions to relevant topics, such as regional policies, climate change, disaster risk management and Natural Capital [32]. The crucial role of GI in urban areas is well-recognized in the regional policies paragraph and has been highlighted by the Urban Agenda for the EU on the sustainable use of land and nature-based solutions and other EU initiatives, such as the European Green Capital and Green Leaf awards. The European Green Deal 'package' further recognizes this value in its newly released Biodiversity Strategy for 2030, acknowledging that biodiversity loss and ecosystem collapse are some of the biggest threats facing humanity, with repercussions for environmental, socio-economic and health systems [33]. Adopted in the midst of the COVID-19 pandemic, this strategy is also a core element of the EU recovery plan. This echoes current research, which warns that habitat fragmentation and degradation and live animal markets increase the risk of diseases spilling over from wildlife into human populations [34]. The Commission's ambition is to ensure that all of the world's ecosystems are restored, resilient and adequately protected by 2050, in line with the 2030 Agenda for Sustainable Development and with the objectives of the Paris Agreement on Climate Change [35]. NBS and the related ecosystem services they provide are well integrated in the Biodiversity Strategy for 2030, along with urban challenges and the role of SUP in the sustainability transition. Paragraph 2.2.8 is dedicated to greening (peri-)urban areas in an effort to stop the loss of resilient natural urban ecosystems. According to the strategy, the promotion of healthy ecosystems, GI and NBS should be systematically integrated into urban planning, including public spaces, infrastructure and the design of buildings and their surroundings. In a stark comparison to the previous EU Biodiversity Strategy 2020, cities are finally being recognized for the central role they play in safeguarding and enhancing biodiversity and for their potential to provide green and blue corridors between larger areas of protected land. Specifically, cities with a population more than 20,000 are called upon 'to develop Urban Greening Plans, including measures to create biodiverse and green urban forests, parks and gardens; urban farms; green roofs and walls; tree-lined streets; urban meadows; and urban hedges. [ ... ] To facilitate this work, the Commission will set up an EU Urban Greening Platform with cities and mayors in 2021 under a new 'Green City Accord' [33].

\subsubsection{Water}

Water is essential for European citizens and the economy, but climate change and environmental degradation are putting pressure on this precious resource. At the beginning of 2000, the European Commission developed two crucial directives on water quality [36] and flood management [37], published in 2000 and 2007. The Water Framework Directive and the Floods Directive requested Member States to develop river basin management plans (RBMPs) and flood risk management plans (FRMPs) to ensure a good quality status of European water and to set up risk management plans to mitigate flood risks in European river basins and coastal areas. The Water Framework Directive recognizes the value of natural water retention measures (NWRMs) and supports their implementation through river basin management plans and the accompanying program of measures (PoM). NWRMs can be seen as NBS applied to the water sector, as an alternative to gray infrastructure (Article 4.7), to achieve and maintain healthy water ecosystems and offer multiple benefits. No specific link to urban areas and SUP is highlighted, except the connection with the Urban Wastewater Directive.

The Flood Directive also recognizes that floods are one of the most common and most dangerous natural hazards affecting European cities. Although FRMPs should take into account the characteristics of the particular catchment area and include the promotion of 
sustainable land use practices, the Flood Directive does not specify what kind of water retention measures are preferable. As with the Water Directive, however, natural water retention measures (NWRMs) are mentioned in the text and can be considered a type of NBS. These measures have the potential to reduce extreme flow discharge and thereby help to level out extreme rain, flood events, etc. Several public authorities at the local and regional levels have utilized this opportunity and implemented NBS to cope with floods in a sustainable way (e.g., relocating dikes, using floodplain forests), but such progressive authorities are still in the minority. The low uptake of NBS to mitigate flood risks is determined by different factors such as traditions, insufficient awareness of the benefits, lack of experience to scale up solutions, lack of capacity to manage or carry out NBS projects, limited financial resources or lack of evidence on the effectiveness and long-term impacts of NBS as compared to structural measures [38]. The Flood Directive suggests consideration of these measures but does not include any obligations as such.

\subsubsection{Coastal Management and Marine Environment}

More than $40 \%$ of the EU population currently lives in coastal regions [39], which are often extremely rich socio-ecological hotspots. These areas are becoming increasingly populated and urbanized [40]. At the same, due to increasing greenhouse gas (GHG) emissions and the impacts of climate change, coastal areas are amongst the most vulnerable areas [41]. GHGs and related ocean acidification is extremely dangerous for the already fragile marine ecosystems. Coastal communities will also be strongly affected by extreme weather events [42] and sea-level rise [43,44], which are expected to accelerate through the 21st Century. Even if emissions substantially decline, sea-level rise will continue to be significant through the 21st century. This poses a major challenge to long-term coastal management.

According to recent research $[45,46]$, ecosystem-based approaches and NBS can greatly support and enhance the resilience of coastal areas and restore the quality and service provisioning of marine ecosystems. An ecosystem-based approach integrates ecological, economic and social objectives in a single holistic approach, respecting ecological limits and carrying capacity, and balancing human use and development needs with ecosystem conservation and protection needs. This approach is acknowledged both by the Marine Strategy Framework Directive [47] and by the proposal for a framework for maritime spatial planning and integrated coastal management [48]. Both documents focus on maintaining ecosystem integrity and functioning to ensure resilience to change and the sustained delivery of ecosystem services.

Maritime and coastal activities are often closely interrelated. This requires maritime spatial plans and integrated coastal management strategies to be coordinated to guarantee the sustainable use of maritime space and management of coastal areas, taking account of social, economic and environmental factors. Although the Marine Strategy Framework Directive requires Member States to achieve a good environmental status in line with the Water Framework Directive, the proposal of wider integrated coastal management also recognizes the complexity of coastal socio-ecological systems. The directive therefore includes the idea of defining cross-sectorial policies to foster coordinated and coherent decision-making to maximize sustainable development. Recognizing that the well-being of populations and the economic viability of many business activities in coastal zones depend on the environmental status of these areas and of the services provided by that specific ecosystem, the directive calls for the development of long-term integrated management tools to enhance the protection of coastal resources, while increasing the efficiency of their use. Despite socio-ecological coastal areas being recognized as crucial socio-ecological systems, the role of local authorities and communities and thus the role of SUP is not explicitly mentioned in the directives. 


\subsubsection{Climate Adaptation and Mitigation}

The use of nature in the context of achieving climate adaptation was first included in the EU White Paper on Adaptation [49], describing the crucial role GI plays in the provision of social and economic benefits to support adaptation under extreme climatic conditions. The first EU Adaptation Strategy was then adopted in 2013 to enhance the preparedness and capacity to respond to foreseen climate impacts at the local, regional, national and EU levels by scaling up climate-resilience [50]. This Strategy explicitly encouraged GI implementation and the application of ecosystem-based adaptation approaches as part of a coordinated European approach to climate adaptation [51]. It underwent a positive evaluation in 2018, demonstrating steady progress in all of its actions.

A new and arguably more ambitious EU Strategy on Adaptation to Climate Change was launched in February 2021 as one of the key priorities of the European Green Deal [52]. The strategy strives to make the EU climate-resilient by 2050, not least by increasing society's adaptive capacity and reducing vulnerability. The strategy has four main objectives: to make adaptation smarter, swifter and more systemic, and to step up international action on adaptation to climate change. Faster adaptation refers to developing and rolling out adaptation solutions to help reduce climate-related risk, increasing climate protection and safeguarding the availability of fresh water. Systemic adaptation, on the other hand, recognizes potential impacts on all levels of society and across all sectors of the economy. Here, the aim is to support the further development and implementation of adaptation strategies and plans at all levels of governance with NBS and local adaptation action listed as two of the three cross-cutting priorities. These objectives are underpinned by 14 actions, several of which are directly relevant for NBS and SUP, including:

- Setting up support for planning and implementation of local adaptation and launching an adaptation support facility under the EU Covenant of Mayors to assist local and regional authorities

- Developing the financial aspects of NBS and fostering the development of financial approaches and products that also cover nature-based adaptation

- Continuing to support Member States to roll out NBS through assessments, guidance, capacity building and EU funding

Green infrastructure, ecosystem-based management and NBS are all highlighted in the document, with NBS being a priority, given their cost-efficiency, multifunctionality and potential to generate diverse benefits. The strategy also highlights that the local level is the 'bedrock of adaptation'.

At the same time, the European Commission is constantly working on climate mitigation actions. The first European Climate Change Program (ECCP) was established in 2000 to help identify the most environmentally and cost-effective policies and measures that could be taken at the European level to cut GHG emissions, according to the targets agreed to in the Kyoto Protocol. In 2007, European leaders started to set even more ambitious targets than the ones embedded in international policies and agreements and the 2020 package was a set of binding legislation to ensure that the EU meets its climate and energy targets for 2020. The same targets have been made more ambitious towards 2030, when the EU commission proposed the new 2030 Climate target plan [53], striving for:

- At least $55 \%$ cuts in greenhouse gas emissions (from 1990 levels)

- At least a 55\% share for renewable energy

- At least a 32.5\% improvement in energy efficiency

Although ecosystem services and NBS are not mentioned within this package, agriculture, land use, land-use change and forestry are mentioned as relevant sectors in the GHG reduction target for 2030. The framework states that accompanying policy measures should also build on the experiences from "greening" under the Common Agricultural Policy and ensure coherence with other EU policies. Although the energy efficiency directive does not include any reference to utilizing NBS for improving energy efficiency and buildings' thermal comfort (i.e., green walls and roofs), the directive does mention 
the crucial role of SUP and actions being taken across Europe to develop local sustainable energy plans (SEPs).

European climate policy is currently facing a crucial moment, on account of the European Green Deal, striving to reach climate-neutrality across the EU by 2050. Climate neutrality foresees an economic model with net-zero greenhouse gas emissions. This objective is at the heart of the Green Deal and is in line with the EU's commitment to global climate action under the Paris Agreement. Currently, the transition to a just climateneutral society is an urgent challenge, as well as an opportunity to build a better future for all. The current proposal for a framework for achieving climate neutrality [53] refers to the establishment of a European Climate Pact (ECP) to engage citizens and communities in climate and environmental action. Within the ECP, to be launched in late 2021, one of the three sectors will include tree-planting, nature regeneration and the greening of urban areas. While the current proposal does not explicitly include the role of SUP or the potential role of NBS to achieve climate neutrality, this could be further reinforced in the final communication.

\subsubsection{Circular Economy}

The circular economy (CE) concept is currently of great interest to policy, scientists and practitioners and is at the center of many business and public debates. The circular economy can be viewed as a way of operationalizing the concept of sustainable development, not just in the business sector, but also in cities' transition pathways [54]. CE promotes a more environmentally sound use of resources, requiring both a deep understanding of and creative thinking about products, industrial processes and services throughout their lifecycles.

The same circular approach is now being adapted and applied to cities, which are responsible for producing around $70 \%$ of global resources and energy, emitting $70 \%$ of all GHGs and generating about 70\% of global waste [55]. Ref. [56] defines a circular city as "a city that practices circular economy principles to close resource loops, in partnership with the city's stakeholders (citizens, community, business and knowledge stakeholders), to realize its vision of a future-proof city".

The circular cities concept is well recognized at the international level, with an increasing number of networks and initiatives arising, such as the Ellen MacArthur Foundation and the Cities 40 (C40) initiatives. Since 2014, the concept is also gaining increasingly attention in European policies as a result of the launch of the EU action plan for the circular economy [57]. The CE package mostly focuses on stimulating Europe's transition towards a circular economy, with measures covering production and consumption, waste management, the market for secondary raw materials and a revised legislative proposal on waste. Under the umbrella of the so-called "closing the loop" concept, the EU action plan focuses mainly on greater recycling and re-use and does not include any reference to a broader understanding of the circular economy and to its potential implementation in cities.

Through the Pact of Amsterdam (2016) and the Urban Agenda process [58], one of the partnerships was called on to provide recommendations to the EU Commission on better knowledge, funding and regulation-the recommendation was that cities would need to work towards a more circular future. The new Circular Economy Action Plan [59] is embedded within the European Green Deal and —in the authors' judgement—-still overlooks land as one of the most crucial and currently at risk non-renewable natural resources. This is likely because it is not easy to include land in consumption and production loops and because the EU has less direct influence on urban development and planning issues than on more concrete environmental aspects. Nevertheless, as stated in the Sustainable and Circular Reuse of Spaces and Buildings Handbook [60], the European Commission, as well as national and regional authorities, should make stronger, binding steps towards the re-use of land and buildings. SUP can potentially play an important role in this respect. 


\subsubsection{Environmental Impact Assessment (EIA) and Strategic Environmental Assessment (SEA)}

The topic of land-use and land change is not only relevant for circular-economy-related policies and actions, but also plays a crucial role within environmental assessment-related strategies and directives. Since the first approval of the Environmental Impact Assessment Directive in 1985, the EU has required projects that could have significant adverse effects on the environment to provide information on measures envisaged to avoid, prevent or reduce such adverse impacts. The Directive for Environmental Impact Assessment (EIA) put in place the concept of environmental assessments on a European scale, with the aim to assess public and private projects with significant negative effects on the environment throughout Europe. An environmental impact assessment report requires the developer to provide information on measures envisaged in order to avoid, prevent or reduce and-if possible - offset likely significant adverse effects on the environment. It further requires a description of reasonable alternatives (for example, in terms of project design, technology, location, size and scale) and an indication of the main reasons for selecting the chosen option, including a comparison of the environmental effects. These requirements encourage more environmentally friendly solutions. NBS are not explicitly mentioned among possible sustainable options, nor is the role of SUP highlighted in this direction. This is, however, to be expected, given the relatively recent emergence of the NBS concept and terminology.

The development of environmental assessment requirements for local, regional and national plans and programs is based on this initial legislative framework, but has since transitioned away from the EIA approach [61]. As such, the EU Strategic Environmental Assessment Directive entered into force in 2001 [62], requiring authorities to undertake an environmental assessment of public sector plans and programs that are likely to affect the environment. The objective of the SEA Directive is to provide a high level of protection for the environment by increasing the integration of environmental considerations in the preparation and adoption of plans and programs, with a view to promoting sustainable development. It sets out standard procedures for undertaking such strategic-level environmental assessments. As the SEA Directive entered into force, it introduced not just the idea of evaluating the sustainability of policies and plans that could negatively impact the environment, but also proposed the comparison of diverse alternatives and more sustainable scenarios for urban and territorial development. In this regard, land use and land change in urban and peri-urban areas remain among the most discussed issues at the planning level. The application of Strategic Environmental Assessments (SEA) has the potential to address these negative impacts by enabling strategic thinking for the integration of environmental factors into decision-making processes, supporting the transition towards environmentally sustainable economic growth in Europe [61]. Although the relevance for SUP is fairly well recognized, NBS are not directly mentioned within the directive, and they are implied as a benchmark for the sustainable alternatives to planning that are required under Article 5. Better integration of NBS within the SEA context has the potential to close gaps between economic ambition and sustainable long-term environmental goals in knowledge-based decision-making.

The nature of the SEA Directive requires an integrated assessment of plans and programs and their potential effect on the environment, linking this to the general European environmental legislative framework and to the diverse sectors presented in this section. The Water Framework Directive, for example, established the key procedural requirement of river basin management plans, thus the link between WFD and the SEA Directive require SEA applications during river basin management plan preparation. Thus, as the SEA Directive supports the implementation of numerous EU directives and strategies (i.e., nitrates, waste, noise and floods) that have various indirect and direct links with NBS, there is potential for strengthening these linkages in the future.

\subsubsection{Green Public Procurement (GPP)}

Public procurement may be an important driver for the further integration and uptake of NBS into markets. Indeed, the public sector can influence green procurement both by 
designing suitable policies and by leveraging "green" markets through the significant dimension of public purchases. The basic concept of green public procurement (GPP) relies on integrating environmental criteria for the procuerement of public products and services. GPP is defined in the European Commission's Communication as "a process whereby public authorities seek to procure goods, services and works with a reduced environmental impact throughout their life cycle when compared to goods, services and works with the same primary function that would otherwise be procured" (EU Commission, 2008). The use of the voluntary EU GPP criteria for public space maintenance has the potential to deploy NBS to considerably reduce environmental impacts in the sector and can help stimulate demand for more sustainable goods and services (e.g., eco-innovations). Among the 20 GPP criteria for specific sectors, at least four of them already mentioned NBS and ES, and could be relevant to boost nature-based innovation within urban areas, as detailed in Table 2.

Table 2. Relevant GPP criteria for NBS and their integration.

\begin{tabular}{cc}
\hline GPP & NBS Integration \\
\hline $\begin{array}{c}\text { Criteria for Office Building } \\
\text { Design, Construction and } \\
\text { Management, 2016 }\end{array}$ & $\begin{array}{c}\text { The integration of NBS, such as green roofs and walls, habitats } \\
\text { in courtyards and patios, sustainable urban drainage systems } \\
\text { (SUDS) and street trees is well acknowledged, also including } \\
\text { references to co-benefits and multifunctionalities of NBS. }\end{array}$ \\
$\begin{array}{c}\text { Criteria for Public Space } \\
\text { Maintenance, 2019 }\end{array}$ & $\begin{array}{c}\text { Specification about gardening products and services could be } \\
\text { relevant for NBS, but are not properly recognized and could be } \\
\text { further integrated. }\end{array}$ \\
$\begin{array}{c}\text { There is a well-documented integration of NBS in the document: } \\
\text { (i) covering the specification of approaches to lower noise } \\
\text { emissions during construction, in the use and maintenance } \\
\text { phase; (ii) introducing water pollution control components and } \\
\text { stormwater retention capacity components, including soft } \\
\text { engineered solutions (e.g., NBS) in the drainage system; (iii) } \\
\text { Maintenance, 2016 } \\
\text { including the potential for habitat creation, notably to reduce } \\
\text { runoff into storm sewers and the overall amount of water } \\
\text { entering local storm sewers or surface waters, thereby } \\
\text { significantly reducing flooding-related damages. }\end{array}$ \\
$\begin{array}{c}\text { There is no specific reference to NBS or innovations in the } \\
\text { Infrastructure, 2013 }\end{array}$ \\
$\begin{array}{c}\text { document, even though phytoremediation could be considered } \\
\text { to integrate and improve the performance of existing } \\
\text { wastewater treatment. }\end{array}$ \\
\hline
\end{tabular}

Three out of four GPP criteria explicitly mentioned and integrated the concept of NBS. Furthermore, as explicitly mentioned in the EU Biodiversity Strategy for 2030, the Commission will further work on public procurement criteria to boost ES and NBS. Local authorities play a key role in introducing GPP into their management procedures and SUP.

\subsection{Identified Gaps between the Recognized and Potential Relevance of the Role of NBS and SUP in the Analyzed Policies}

According to the analysis of the qualitative judgements, further detailed and summarized in Appendix A, the different sectors have been positioned in Figure 1 according to the current gaps in considering the recognized and potential relevance of NBS and SUP in the explored policy sectors.

Figure 1 shows that the gaps in considering SUP are generally higher than those in considering NBS. Biodiversity policies, overarching environment programs and circular economy packages show no gaps in recognizing NBS. Instead, they embed the role of nature well in reaching the diverse policy targets and objectives. On the other hand, while environmental policies well acknowledge the role of SUP, the circular economy package presents a low recognition of SUP despite this sector being of great relevance for urban 
areas. On the other hand, GPPs, EIA, SEA and the Water Directive present medium gaps between both NBS and SUP recognition and their possible role. Finally, climate mitigation, the Floods Directive and the marine environment present the highest gaps in terms of the recognition of both SUP and NBS, highlighting the highest potential for sectoral improvement, as further discussed below.

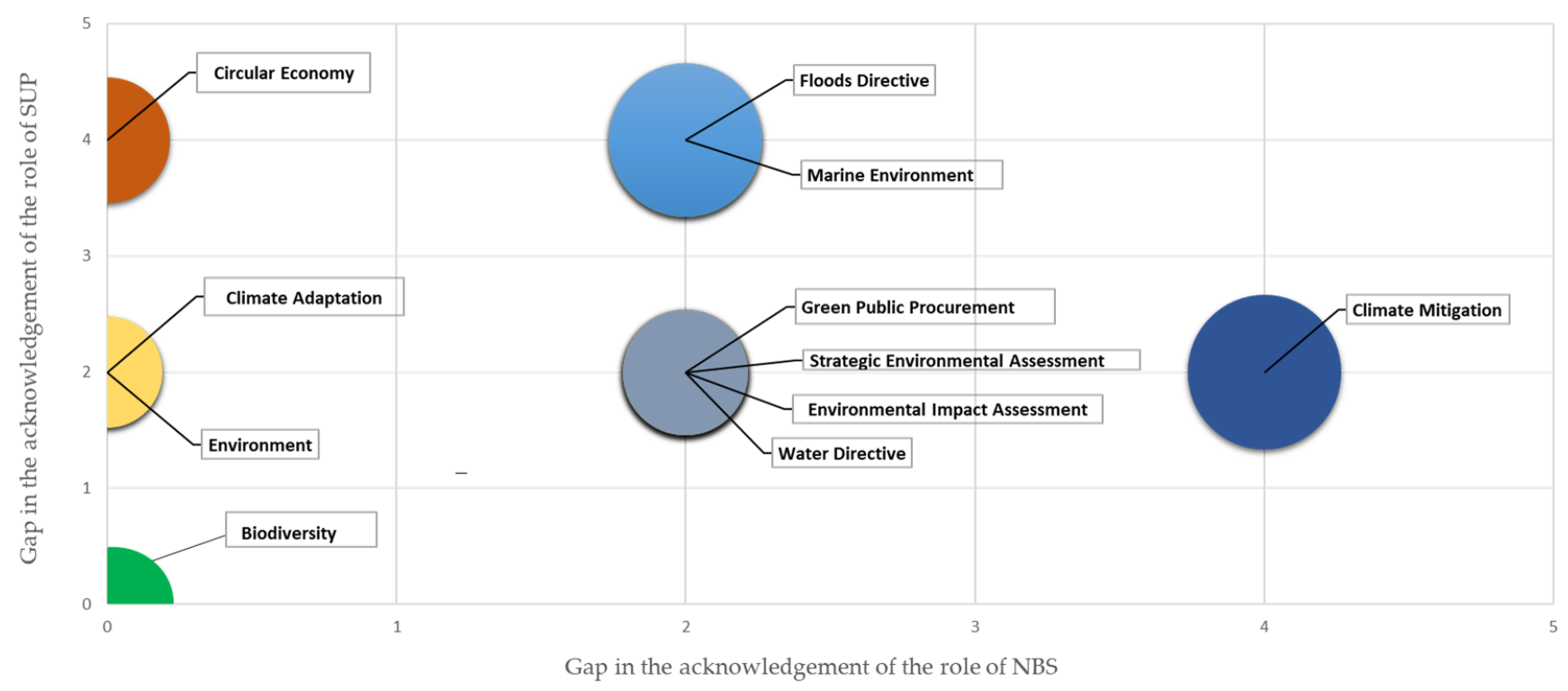

Figure 1. Identified gaps between the recognized and the potential relevance of role of NBS ( $x$-axis) and SUP ( $y$-axis) in reaching EU environmental policy targets and objectives. Policy sectors lying on the axis (gap value $=0$ ) present no gap in the acknowledgement of the role of NBS and/or SUP. The higher the gap number (up to 4), the higher the gap between the recognized and the potential relevance of role of NBS and SUP. Detailed information about the gaps recognized by the experts' judgments is provided in Appendix A.

\section{Discussion}

The analysis carried out in the outlined policy sectors highlights a diverse level of integration of SUP and NBS in the current EU environmental policy framework. The reasons behind the variance could be twofold. On the one hand, the topic of NBS has been emerging in the last decade as a research and innovation priority of the European Commission [24] and there is a strong willingness of the Commission to mainstream the concept across policy sectors as part of its effort to become a global leader in NBS. On the other hand, local authorities in cities do not have direct responsibility for the implementation of such strategies, even though they are asked to develop dedicated plans (e.g., sustainable energy plans, urban greening plans and climate adaptation plans), calling for increased coordination and a strong response from urban areas.

Climate adaptation and biodiversity policies showed a wide understanding and good integration of both the natural and urban environments. Although the EU Adaptation Strategy has already made noteworthy progress as compared to its predecessor, significant room remains to strengthen the requirements and accompanying support for Member States (e.g., in the form of guidance for local authorities and decision-makers, civil society, private businesses and conservation practitioners), foster wider cross-sectoral integration and uptake and generate critical knowledge to fill remaining gaps. Finally, the links between policy and science should be extended and strengthened within the climate adaptation strategy. Similarly, concerning the EU Biodiversity Strategy for 2030, stronger coordination and work will be needed in terms of strengthening monitoring, dissemination and capacity building actions in order to obtain valuable and long-lasting results. Even though the EU Biodiversity Strategy for 2030 recognizes the crucial role nature plays in cities and invites urban areas to further develop in this area, it remains a mainly non- 
binding document and potentially faces challenges in its enforcement across sectoral policies (such as agriculture). However, the European Commission is developing a binding EU Restoration Plan by the end of 2021 to foster and implement its restoration targets in the EU Member States. Ambitious and measurable targets have been set, for example, for the increase in protected areas, improvement of the conservation status of habitats and species, the restoration of rivers, organic farming and the reduction of pesticides. These objectives will be monitored regularly through a set of appropriate indicators (being part of the new European biodiversity governance framework) to measure progress towards achieving the objectives of the strategy and to take corrective action if necessary.

The full implementation and enforcement of European environmental legislation requires political commitment and the prioritization of financial and human resources. To tap into this potential when proposing further legislation and guidance on GPP, the European Commission should integrate criteria and monitoring to boost NBS. The path towards biodiversity protection, conservation and enhancement is still long and this new strategy could pave the way towards greening European cities. Instruments like the (voluntary) urban greening plans foreseen under the Biodiversity Strategy could be strengthened by explicitly linking them to climate change mitigation and adaptation, which is currently lacking. In contrast, the planned EU Nature Restoration Plan, being developed as part of the EU Biodiversity Strategy for 2030, will serve as a strong, legally binding policy to mandate, promote and support restorative NBS implementation.

The marine environment, water and climate mitigation sectors present the largest gaps regarding the consideration of both NBS and SUP. These sectors do not recognize a specific role of SUP in reaching the foreseen objectives. However, we suggest that SUP would be able to play a crucial role in supporting the implementation of these policies. Specifically, in the marine and coastal environment, the integration of the role of local authorities and SUP in the current proposal for a framework for maritime spatial planning and integrated coastal management is currently very low, whereas the potential of including the role of coastal urban areas or communities is potentially very high and relevant in order to reach a consensus in coastal management and to further boost the upscaling of NBS through co-design and participatory processes.

With regards to climate mitigation, the current Proposal for a European climate law to ensure climate neutrality by 2050, following the previous 2030 Climate target plan, does not include references to potential NBS for improving energy efficiency and buildings ${ }^{\prime}$ thermal comfort (e.g., green walls and roofs), despite the relevance of this concept to the construction sectors and their potential to be affected by decisions made by local authorities through SUP, e.g., sustainable energy plans (SEPs). The recent increase in the EU greenhouse gas emissions reduction target from 40\% to 55\% from 1990 levels by 2030 means that many National Energy and Climate Plans may need to be revised in response to this new, more ambitious target. This opens a significant window of opportunity to better integrate climate nature-based solutions within other policy agendas and augment the role of cities in this regard.

The water sector, encompassing the Water and the Floods Directives, could be further improved in terms of both NBS and SUP. According to the authors' judgement, the role of SUP in the Floods Directive should be further strengthened, with better connections to the FRMPs and the local SUP tools and instruments. The recent Water Fitness Check, considering both directives, recommends a further integration of ES and NBS in the documents. A more ambitious transition towards such solutions is needed, with local authorities considering and assessing NBS co-benefits in all their projects and plans, including health and wellbeing benefits-not least in light of the COVID-19 pandemic. To further boost the uptake of these kinds of solutions in urban areas and to better embed those into SUP practices and planning, FRMPs may include an assessment of the potential co-benefits generated from the implementation of NBS in urban and peri-urban areas (e.g., socio-economic benefits from the recreational aspects, climate change mitigation, habitat for native species, etc.) and consider them as an added value. 
The circular economy and overarching environmental programs deeply root NBS in their respective policy documents. Nevertheless, the role of SUP in progress towards a sustainable transition is largely neglected in circular economy packages and could also be better addressed in environmental impact assessment policies. The Circular Cities and Regions Initiative (CCRI) is part of the new Circular Economy Action Plan and will focus on the implementation of circular solutions at the local and regional scales. Even though cities and SUP are not at the core of the New Circular Economy Action Plan, the CCRI was launched in October 2020 and will provide a contribution to the implementation of the European Green Deal and the EU Bioeconomy Strategy, explicitly recognizing the crucial role of cities in this transition and pushing spatial planning to intervene in markets to provide long-term space for low-value, circular activities. In this sense, even though a European Directive on soil and land use would be desirable, it could be a first step to increase the integration of land use and land change issues in current circular economy and environmental assessment policies and directives. Better integration of scenario development and the evaluation of alternatives into SUP are required to ensure informed decision-making processes, which should include land use and change among their priority assessment criteria. This could pass through a revision of the current SEA, with clear land take indicators and further ecosystem-based approaches being developed [63]. The SEA would benefit from an integrated analysis of co-benefits for nature-based solutions, ranging from cultural ecosystem services such as recreational opportunities to climate mitigation, as these can be considered the strongest motivations for promoting NBS [22,23]. If the SEA Directive were not only to ensure integration of environmental assessments across policies, plans and strategies, but to explicitly rank opportunities for nature-based solutions above alternative solutions on the basis of higher co-benefits across determining factors (i.e., human health, biodiversity and material assets (SEA Directive, Article 3)), this would have a great effect across the European legislative framework. The final Action Plan of the Partnership on Sustainable Use of Land and Nature-based Solutions has pointed out that a reference to 'land take' is missing in SEAs. The missing consideration of land take could prove to be a valuable entry point for NBS. The future integration of this concept in the directive would largely support a rapid upscaling of NBS at the city and territorial scales.

Regarding GPP, according to [64], we suggest that adopting a challenge-based approach to procurement that specifies desired outcomes could open up the market to tailormade NBS. Overall, the role of SUP as a potentially relevant sector for including GPP into practice can also serve to support the more rapid upscaling of GPP (and thus, relevant NBS) into business-as-usual procedures.

Finally, the authors did not observe any gaps in the integration of NBS and SUP into the biodiversity sector, acknowledging that the recently released Biodiversity Strategy for 2030 embeds both NBS and SUP in various aspects of the legislation.

\section{Conclusions}

Following the New Urban Agenda [16] and the Pact of Amsterdam [58], there is an important debate occurring throughout the EU on 'urban matters'. As stated in the Pact (p. 3), 'urban areas play a key role in pursuing the EU 2020 objectives and in solving many of its most pressing challenges [ ... ] the success of European sustainable urban development is highly important for the economic, social and territorial cohesion of the European Union and the quality of life of its citizens'. For this reason, this paper analyzed the recognized and potential role of NBS and SUP in EU environmental policies. For this analysis, a selection of sectors was made, focusing on their relevance to the natural and urban environments. Specifically, policies relating to water, environmental assessment, coastal and marine areas, biodiversity, climate change adaptation and mitigation, the circular economy and public procurement were included. In addition, overarching strategic documents relating to the environment were taken into consideration, such as the Environmental Action Program and the European Green Deal. With an increasing focus on securing a sustainable future, the evidence and awareness of the potential of natural capital and NBS 
to support progress towards urban sustainability have continued to grow. Since then, NBS and related concepts such as ecosystem-based adaptation, green infrastructure and natural water retention measures are being increasingly integrated into a range of environmental, climate and biodiversity policies at the EU level. Most of these policies have a direct impact on cities through their requirements or via proposed recommendations, which are to be integrated into local policies, strategies and plans. However, their impact also depends on how well they are implemented on the ground, which remains an ongoing challenge. The biggest gaps have been identified in the areas of climate mitigation, flood management and the marine environment, followed by GPP, environmental assessment directives, water directives and the circular economy. Climate adaptation, environmental programs and biodiversity policies integrated both NBS and SUP concepts very well, although they were notably embedded into strategic and non-binding documents and programming guidelines. Concerning the circular economy, with strong abilities in terms of development and planning issues, municipalities can and should include the circular re-use of abandoned or underused properties into their urban development policies and strategies. This process can be boosted by the support provided by established and proposed networks and initiatives to provide key assistance to cities, e.g., the European Urban Initiative, the Intelligent Cities Challenge Initiative, the Circular Cities and Regions Initiative and the Green City Accord.

Moreover, based on our policy analysis, a stronger connection between sectorial environmental policies, cohesion funds and urban realities and challenges would likely support and enhance the transition towards sustainable and more inclusive cities.

A better use of the EU's diverse structural and investment funds would also be valuable in order to support NBS. The EU Cohesion Policy Funds (ERDF Art.7-9) has, for example, earmarked 5\% of its funding for sustainable urban development, including the implementation of NBS. Other examples of relevant European funding programs include LIFE, INTERREG, Horizon2020 and the Urban Innovative Actions initiative. This is in line with the new European Green Deal, which supports the integration of environmental sectors into wider EU policies and strategies, putting them at the core of the EU Recovery Plan. Nevertheless, although the European Green Deal strongly embeds the concept of NBS into dedicated strategies and documents (e.g., the Biodiversity Strategy for 2030 and the new EU Climate Adaptation Strategy), the broader alignment of NBS with wider strategic priorities could also help to access not only budgets and existing capacities dedicated for climate change mitigation and adaptation, but also those earmarked for other related prioritized paradigms. The upcoming EU Restoration Plan, which will also cover urban areas, provides a huge opportunity to foster the implementation of NBS in Europe, but also requires a close coordination with the development of the Urban Greening Plans in European municipalities.

Moreover, relevant policies need to systematically consider the effects of implementing NBS beyond their primary objective (e.g., flood protection), recognizing the multifunctionality of NBS, which also hold the potential to deliver socio-cultural benefits and a wide range of ecosystem services. Targeted guidance for Member States on how to integrate and foster NBS in policy implementation and exchanges of good practices between Member States could prove to be helpful.

Considering the current policy framework and recent events, such as the current COVID-19 pandemic, the European Union is now at a crossroads. The COVID-19 pandemic poses huge challenges, but also offers a great opportunity to set up a recovery plan based on socio-economic, environmental and climate justice considerations. The new European Green Deal is a crucial step in the EU recovery plan and serves as an important step towards a new growth strategy-one which aims to transform the EU into a fair and prosperous society with a modern, resource-efficient and competitive economy. Ensuring not just a competitive economy, but also an inclusive and sustainable transition of the EU by maintaining and enhancing European citizen health, well-being and quality of life requires a further greening of sectoral policies through increased integration of NBS and ES, as well as augmented recognition of the crucial role of urban areas in sustainable and inclusive growth and a long-term political commitment. 
Author Contributions: Conceptualization, C.d.L., S.N., M.D. and S.T.; methodology, C.d.L.; formal analysis, C.d.L., S.N. and M.D.; writing-original draft preparation, C.d.L.; writing-review and editing, S.N., M.D. and S.T.; visualization, C.d.L.; supervision, S.T. All authors have read and agreed to the published version of the manuscript.

Funding: This research received no external funding.

Institutional Review Board Statement: Not applicable.

Informed Consent Statement: Not applicable.

Data Availability Statement: All relevant data collected during the work are available at Appendix A.

Acknowledgments: This work has been partially conducted within the implementation of Action 6 of the Urban Agenda on Sustainable Land Use and Nature Based Solutions.

Conflicts of Interest: The authors declare no conflict of interest.

\section{Appendix A}

Appendix A contains the detailed authors' judgments for each policy analyzed. Judgments illustrated in this Appendix refer to the recognized role $(R)$ and to the potential role $(\mathrm{P})$ of SUP and NBS in each policy analyzed.

Table A1. Environment as an overarching issue.

\begin{tabular}{ccccc}
\hline Overall Objective/s and Reference to SUP and NBS & \multicolumn{2}{c}{ Role of SUP } & Role of NBS \\
\hline 7th Union Environment Action (EAP) Program up to 2020 & R & $P$ & $R$ & $P$ \\
\hline
\end{tabular}

Objective: guides European environmental policy towards 2020 and sets a long-term direction and a vision until 2050 (to live within the planet's ecological limits and in a healthy environment in which biodiversity is protected, valued and restored). Relevant instruments are:

Thematic priority objective 1-to protect, conserve and enhance the Union's natural capital:

- Maritime spatial planning and integrated coastal management can play an effective role in coordinating the sustainable use of marine waters and coastal zones when applying the ecosystem-based approach to the management of different sectoral activities in those areas.

- Ecosystem-based approaches to climate change mitigation and adaptation, which also benefit biodiversity and the provision of other ecosystem services.

- In combination with the full implementation of the Nature Directives, further enhance natural capital and increase ecosystem resilience to offer cost-effective options for climate change mitigation and adaptation and disaster risk management.

- Mapping and assessment of ecosystems and their services for data availability, and the 'no net loss' initiative (2015) will contribute to maintaining the stock of natural

Low High (5)

High High capital at a variety of scales.

- Thematic priority objective 3-to safeguard citizens from environment-related pressures and risks to health and wellbeing:

- Measures to enhance ecological and climate resilience, such as ecosystem restoration and green infrastructure.

- $\quad$ Enabling framework priority objective:

- Incorporating green infrastructure into related plans and programs can help overcome fragmentation of habitats and preserve or restore ecological connectivity, enhance ecosystem resilience and thereby ensure the continued provision of ecosystem services, including carbon sequestration and climate adaptation, while providing healthier environments and recreational spaces for people to enjoy.

Biodiversity conservation through actions such as the reintroduction of nature into the urban environment and urban landscaping is increasingly evident

The 8th Environment Action Program-Bringing the Trends Together, 2030

Objective: the first communication regarding the 8th EAP, not yet published, underlies the urgent need to act, as several planetary boundaries have been crossed and as climate change, pollution, the loss of biodiversity and accelerating demands on natural resources are N/A

High (5)
High

(5)
High 
Table A1. Cont.

\begin{tabular}{ccc}
\hline Overall Objective/s and Reference to SUP and NBS & Role of SUP & Role of NBS \\
\hline European Green Deal-under development & \\
\hline
\end{tabular}

Overall objective: Outlines a commitment to tackling climate and environmental-related challenges and aims to make Europe climate-neutral, protecting the EU's natural capital and improving human well-being.

Relevant instruments

- $\quad$ Adopting a new, more ambitious EU strategy on adaptation to climate change. Work on climate adaptation should continue to influence public and private investments, including in NBS. It will be important to ensure that across the EU, investors, insurers, businesses, cities and citizens are able to access data and to develop instruments to integrate climate change into their risk management practices.

- $\quad$ Strengthening a sustainable 'blue economy' to alleviate the multiple demands on land resources and tackle climate change, emphasizing aquatic and marine resources and NBS, including healthy and resilient seas and oceans

Medium High High High

(3) (5) (5)

- Developing the Biodiversity Strategy for 2030 to halt the loss of biodiversity by protecting and restoring ecosystems and biodiversity, including proposals to green European cities and increase biodiversity in urban spaces.

- Mobilizing research and fostering innovation:

At least 35\% of the budget of Horizon Europe will fund new solutions for climate, which are relevant for the Green Deal.

Four 'Green Deal Missions' will help deliver large-scale changes in, e.g., climate change adaptation, oceans, cities and soil.

The Horizon Europe program will involve local communities in working towards a more sustainable future, in initiatives that seek to combine societal pull and technological push.

Table A2. Biodiversity.

\begin{tabular}{|c|c|c|c|c|}
\hline \multirow{2}{*}{$\begin{array}{c}\text { Overall Objective/s and Reference to SUP and NBS } \\
\text { Habitats Directive, } 1992\end{array}$} & \multicolumn{2}{|c|}{ Role of SUP } & \multicolumn{2}{|c|}{ Role of NBS } \\
\hline & $\mathbf{R}$ & $\mathbf{P}$ & $\mathbf{R}$ & $\mathbf{P}$ \\
\hline $\begin{array}{l}\text { Supports the protection, creation, restoration and sustainable management of habitats as } \\
\text { part of Natura 2000, providing benefits to species, habitats and society (e.g., preserving a } \\
\text { community's natural heritage, creating green recreational areas). Instruments include } \\
\text { the designation of protected areas (Sites of Community Importance and Special Areas of } \\
\text { Conservation) and Natura } 2000 \text { management plans. }\end{array}$ & $\begin{array}{l}\text { Medium } \\
\text { (3) }\end{array}$ & $\begin{array}{l}\text { Medium } \\
\text { (3) }\end{array}$ & $\begin{array}{l}\text { High } \\
(5)\end{array}$ & $\begin{array}{l}\text { High } \\
(5)\end{array}$ \\
\hline
\end{tabular}

\section{Birds Directive, 1979, revised 2009}

Supports the conservation of all naturally occurring wild bird species in the territory of the Member States by employing measures to preserve, maintain and re-establish a sufficient diversity and area of habitats and biotopes for these species. Instruments include the creation of protected areas and biotopes (such as Special Protection Areas for particularly threatened bird species and all migratory birds); upkeep and management in accordance with the ecological needs of habitats inside and outside the protected zones; and the re-establishment of destroyed biotopes. Particular attention is payed to wetland protection.

Low How High

$\begin{array}{llll}(1) & (1) & (5) & (5)\end{array}$

\section{Green Infrastructure Strategy}

Aims to improve information, strengthen the knowledge base, promote innovation and improve access to finance surrounding GI. The strategy is implemented within the context of existing legislation, policy instruments and funding mechanisms. GI features in cities deliver health-related benefits such as clean air and better water quality. Healthy ecosystems also reduce the spread of vector-borne diseases. Implementing green infrastructure features in urban areas creates a greater sense of community, strengthens High High High High the link with voluntary actions undertaken by civil society and helps combat social exclusion and isolation. These features benefit the individual and the community physically, psychologically, emotionally and socio-economically. 
Table A2. Cont.

\begin{tabular}{cccc}
\hline Overall Objective/s and Reference to SUP and NBS & \multicolumn{2}{c}{ Role of SUP } & Role of NBS \\
\hline EU Biodiversity Strategy up to 2030 & R & $P$ & $R$ \\
\hline
\end{tabular}

This is part of the European Green Deal, and acknowledges that Biodiversity loss and ecosystem collapse are one of the biggest threats facing humanity in the future.

Nature-based solutions and ecosystem services are both mentioned from the very beginning of the document

Relevant Instruments:

- $\quad$ New EU Nature Restoration Plan, supporting the recovery of nature, limiting soil sealing and urban sprawl and tackling pollution and invasive alien species

- $\quad$ Recognized the need for stronger implementation support and enforcement is required

- $\quad$ Proposal for legally binding EU nature restoration targets

- $\quad$ EU Soil Thematic Strategy in 2021

High High High High

(5) (5) (5) (5)

- New section dedicated to greening urban and peri-urban areas

- $\quad$ This strategy aims to stop the loss of green urban ecosystems

- Cities with a population above 20,000 citizens are called upon to develop urban greening plans

- New European biodiversity governance framework

In stark comparison to the previous EU Biodiversity Strategy, cities are finally being recognized for the central role they play in safeguarding and enhancing biodiversity, and in providing green and blue corridors between larger areas of protected land.

$\begin{array}{lll}\text { Gaps Recognized by Experts' Judgement } & 0 & 0\end{array}$

Table A3. Water.

\begin{tabular}{|c|c|c|c|c|}
\hline \multirow{2}{*}{$\begin{array}{c}\text { Overall Objectives and References to SUP and NBS } \\
\text { Water Framework Directive (WFD) }\end{array}$} & \multicolumn{2}{|c|}{ Role of SUP } & \multicolumn{2}{|c|}{ Role of NBS } \\
\hline & $\mathbf{R}$ & $\mathbf{P}$ & $\mathbf{R}$ & $\mathbf{P}$ \\
\hline $\begin{array}{l}\text { Aims to achieve good ecological and chemical status of surface waters and good } \\
\text { quantitative and chemical status for groundwater. Recognizes the value of NWRM and } \\
\text { supports implementation through river basin management plans (RBMPs) and the } \\
\text { accompanying program of measures (PoM). Restorative NWRMs are particularly } \\
\text { relevant for the PoM, e.g., restoring and recreating wetlands for water resource } \\
\text { protection, natural bank stabilization and re-meandering, the restoration of lakes and } \\
\text { floodplain restoration. NWRMs are seen as GI applied to the water sector, as an } \\
\text { alternative to gray infrastructure (Article 4.7) to achieve and maintain healthy water } \\
\text { ecosystems and offer multiple benefits. In the agriculture sector, agricultural soil } \\
\text { moisture conservation practices can be linked to agricultural NWRMs. }\end{array}$ & $\begin{array}{l}\text { Low } \\
(1)\end{array}$ & $\begin{array}{l}\text { Medium } \\
\text { (3) }\end{array}$ & $\begin{array}{l}\text { Medium } \\
\text { (3) }\end{array}$ & $\begin{array}{l}\text { High } \\
\text { (5) }\end{array}$ \\
\hline Gaps Recognized by Experts' Judgement & & 2 & 2 & \\
\hline
\end{tabular}

Establishes a framework for the assessment and management of flood risks and aims at reducing adverse consequences of floods for human health, the environment, cultural heritage and economic activities. Floodplains are considered to be natural retention areas, with a preliminary flood risk assessment (Article 4.2) applied to assess potential risks. The flood risk management plans (Article 7) take into account the characteristics of the particular river basin or sub-basin, including the promotion of sustainable land use practices and the improvement of water retention. 
Table A4. Marine environment and coastal areas.

\begin{tabular}{|c|c|c|c|c|}
\hline \multirow{2}{*}{$\begin{array}{c}\text { Overall Objectives and References to SUP and NBS } \\
\text { Marine Strategy Framework Directive, } 2008\end{array}$} & \multicolumn{2}{|c|}{ Role of SUP } & \multicolumn{2}{|c|}{ Role of NBS } \\
\hline & $\mathbf{R}$ & $\mathbf{P}$ & $\mathbf{R}$ & $\mathbf{P}$ \\
\hline $\begin{array}{l}\text { Marine strategies aim to apply an ecosystem-based approach to the management of human } \\
\text { activities, ensuring that the collective pressure of such activities is kept within levels } \\
\text { compatible with the achievement of good environmental status and that the capacity of marine } \\
\text { ecosystems to respond to human-induced changes is not compromised, while enabling the } \\
\text { sustainable use of marine goods and services by present and future generations. }\end{array}$ & & & & \\
\hline $\begin{array}{l}\text { - } \quad \text { Sustainable development and use of marine and coastal space and resources } \\
\text { - Preservation, protection and improvement of the environment/conservation and } \\
\text { recovery of ecosystems, including resilience to climate change impacts } \\
\text { Enabling a sustainable economy and a strong, healthy and just society within } \\
\text { environmental limits }\end{array}$ & $\begin{array}{l}\text { Low } \\
(1)\end{array}$ & Medium & $\begin{array}{l}\text { High } \\
(5)\end{array}$ & $\begin{array}{l}\text { High } \\
\text { (5) }\end{array}$ \\
\hline $\begin{array}{l}\text { Socio-ecological coastal areas are recognized within the directives as crucial socio-ecological } \\
\text { systems, but the role of local authorities and communities is not explicitly mentioned in the } \\
\text { directives, nor is the role of nature in supporting their transition towards sustainability and } \\
\text { climate resilience. } \\
\text { Programs of measures and subsequent action by Member States should be based on an } \\
\text { ecosystem-based approach to the management of human activities }\end{array}$ & & & & \\
\hline
\end{tabular}

\section{Proposal for a Framework for Maritime Spatial Planning and Integrated Coastal Management}

Key principles:

- Preservation, protection and improvement of the environment/conservation and recovery of ecosystems, including resilience to climate change impacts

- Enabling a sustainable economy and a strong, healthy and just society within environmental limits

- $\quad$ Preservation of coastal zones for present and future generations

- Conservation, restoration and management of coastal ecosystems, ecosystem services and nature, coastal landscapes and islands

Low High Medium High

(1) (5) (3) (5)

Nevertheless, even though $40 \%$ of the population live in coastal regions, the role of cities and urban areas in sustainable management of coastal water is not directly mention in the proposal directive.

$$
\text { Gaps Recognized by Experts' Judgement }
$$

Table A5. Climate Change.

\begin{tabular}{cccc}
\hline Overall Objectives and References to SUP and NBS & Role of SUP & Role of NBS \\
\hline Climate Adaptation & & & \\
\hline Climate Change Adaptation Strategy, 2021 & R & P & R \\
\hline
\end{tabular}

Two of the four key objectives of the EU Adaptation Strategy focus on speeding up adaptation across the board and making it more systemic. Faster adaptation refers to developing and rolling out adaptation solutions to help reduce climate-related risk, increasing climate protection and safeguarding the availability of fresh water. Systemic adaptation, on the other hand, recognizes potential impacts on all levels of society and across all sectors of the economy. Here, the aim is to support the further development and implementation of adaptation strategies and plans at all levels of governance, with NBS and local adaptation action listed as two of the three cross-cutting priorities. In the area of systemic adaptation, the strategy highlights that the local level is the bedrock of adaptation, as well as acknowledging the importance of NBS. Accordingly, NBS and SUP relevant actions by the Commission include:

$\begin{array}{cccc}\text { Medium } & \text { High } & \text { High } & \text { High } \\ (3) & (5) & (5) & \text { (5) }\end{array}$

- Setting up support for the planning and implementation of local adaptation and launching an adaptation support facility under the EU Covenant of Mayors to assist local and regional authorities

- Developing the financial aspects of NBS and fostering the development of financial approaches and products that also cover nature-based adaptation

- Continuing to support Member States to roll out NBS through assessments, guidance, capacity building and EU funding 
Table A5. Cont.

\begin{tabular}{|c|c|c|c|c|}
\hline Overall Objectives and References to SUP and NBS & \multicolumn{2}{|c|}{ Role of SUP } & \multicolumn{2}{|c|}{ Role of NBS } \\
\hline Gaps Recognized by Experts' Judgement & \multicolumn{2}{|c|}{2} & \multicolumn{2}{|c|}{$\mathbf{0}$} \\
\hline \multicolumn{5}{|l|}{ Climate Mitigation } \\
\hline \multicolumn{5}{|l|}{ Proposal for a European climate law to ensure climate neutrality by 2050} \\
\hline $\begin{array}{l}\text { The European Council has established building a climate-neutral, green, fair and social } \\
\text { Europe as one of the main four priorities in its Strategic Agenda for 2019-2024. This } \\
\text { proposal aims to establish the framework for achieving EU climate neutrality. } \\
\text { No specific reference to urban areas is given in the proposal. Nevertheless, the European } \\
\text { Climate Pact, to be launched in the last quarter of 2020, will include tree-planting, nature } \\
\text { regeneration and greening of urban areas as one of the main areas of focus. }\end{array}$ & $\begin{array}{c}\text { Low } \\
(1)\end{array}$ & $\begin{array}{l}\text { High } \\
\text { (5) }\end{array}$ & $\begin{array}{l}\text { Medium } \\
\text { (3) }\end{array}$ & $\begin{array}{c}\text { High } \\
\text { (5) }\end{array}$ \\
\hline Gaps Recognized by Experts' Judgement & & & 2 & \\
\hline
\end{tabular}

Table A6. Circular Economy.

\begin{tabular}{|c|c|c|c|c|}
\hline \multirow{2}{*}{$\begin{array}{c}\text { Overall Objectives and References to SUP and NBS } \\
\text { Circular Economy Action Plan } 2015\end{array}$} & \multicolumn{2}{|c|}{ Role of SUP } & \multicolumn{2}{|c|}{ Role of NBS } \\
\hline & $\mathbf{R}$ & $\mathbf{P}$ & $\mathbf{R}$ & $\mathbf{P}$ \\
\hline $\begin{array}{l}\text { Aims to help stimulate Europe's transition towards a circular economy, boost global } \\
\text { competitiveness, foster sustainable economic growth and generate new jobs. It establishes } \\
\text { a concrete and ambitious program of action, with measures covering production and } \\
\text { consumption to waste management and the market for secondary raw materials and a } \\
\text { revised legislative proposal on waste. The proposed actions will contribute to "closing the } \\
\text { loop" of product lifecycles through greater recycling and re-use to benefit the environment } \\
\text { and economy. }\end{array}$ & $\begin{array}{l}\text { Low } \\
(1)\end{array}$ & $\begin{array}{l}\text { High } \\
(5)\end{array}$ & $\begin{array}{c}\text { Low } \\
(1)\end{array}$ & $\begin{array}{l}\text { Medium } \\
\text { (3) }\end{array}$ \\
\hline
\end{tabular}

\section{Proposal of a Circular Economy Action Plan focusing on sustainable resource use, 2020}

The new Water Reuse Regulation will encourage circular approaches to water reuse in agriculture. The Commission will facilitate water reuse and efficiency, including in industrial processes.

Furthermore, the Commission will develop an Integrated Nutrient Management Plan, with a view to ensuring more sustainable application of nutrients and stimulating the markets for recovered nutrients. The Commission will also consider reviewing directives on wastewater treatment and sewage sludge and will assess natural means of nutrient removal, such as algae. The proposed European Urban Initiative, the Intelligent Cities Challenge Initiative, and the Circular Cities and Regions Initiative will provide key assistance to cities.

Low High Medium Medium The circular economy will be among the priority areas of the Green City Accord. The Circular Cities and Regions Initiative (CCRI) is part of the new Circular Economy Action Plan and will focus on the implementation of circular solutions at the local and regional scales. The CCRI will also provide a contribution to the implementation of the European Green Deal and the EU Bioeconomy Strategy. The Green City Accord will support cities in their efforts to achieve cleaner and healthier environments, thereby improving the quality of life of city dwellers. It will be launched in October 2020.

$$
\text { Gaps Recognized by Experts' Judgement }
$$

$\begin{array}{llll}(1) & \text { (5) } & \text { (3) }\end{array}$

Table A7. Environmental Impact.

\begin{tabular}{|c|c|c|c|c|}
\hline \multirow{2}{*}{$\begin{array}{l}\text { Overall Objectives and References to SUP and NBS } \\
\text { Environmental Impact Assessment Directive (EIA) }\end{array}$} & \multicolumn{2}{|c|}{ Role of SUP } & \multicolumn{2}{|c|}{ Role of NBS } \\
\hline & $\mathbf{R}$ & $\mathbf{P}$ & $\mathbf{R}$ & $\mathbf{P}$ \\
\hline $\begin{array}{l}\text { An environmental impact assessment report requires the developer to provide } \\
\text { information on measures envisaged in order to avoid, prevent or reduce and, if } \\
\text { possible, offset likely significant adverse effects on the environment, as well as } \\
\text { provide a description of the reasonable alternatives (for example in terms of project } \\
\text { design, technology, location, size and scale) and an indication of the main reasons } \\
\text { for selecting the chosen option, including a comparison of the environmental } \\
\text { effects. These requirements encourage more environmentally-friendly solutions. }\end{array}$ & $\begin{array}{l}\text { Low } \\
(1)\end{array}$ & $\begin{array}{l}\text { Medium } \\
\text { (3) }\end{array}$ & $\begin{array}{l}\text { Low } \\
(1)\end{array}$ & $\begin{array}{l}\text { Medium } \\
\text { (3) }\end{array}$ \\
\hline
\end{tabular}


Table A7. Cont.

\begin{tabular}{|c|c|c|c|c|}
\hline Overall Objectives and References to SUP and NBS & \multicolumn{2}{|c|}{ Role of SUP } & \multicolumn{2}{|c|}{ Role of NBS } \\
\hline Gaps Recognized by Experts' Judgement & \multicolumn{2}{|c|}{2} & \multicolumn{2}{|c|}{2} \\
\hline \multicolumn{5}{|l|}{ Strategic Environmental Assessment Directive (SEA) } \\
\hline $\begin{array}{l}\text { The criteria to determine whether a project/plan/policy will negatively impact the } \\
\text { environment would all favor greener solutions over traditional/gray infrastructure. } \\
\text { By requiring all applicants (contractors and planners) to review 'reasonable } \\
\text { alternatives', this can encourage more natural or environmentally-friendly } \\
\text { solutions to economic/social development. }\end{array}$ & $\begin{array}{l}\text { Medium } \\
\text { (3) }\end{array}$ & $\begin{array}{l}\text { High } \\
\text { (5) }\end{array}$ & $\begin{array}{l}\text { Medium } \\
\text { (3) }\end{array}$ & $\begin{array}{l}\text { High } \\
\text { (5) }\end{array}$ \\
\hline Gaps Recognized by Experts' Judgement & & & & \\
\hline
\end{tabular}

Table A8. Green Public Procurement.

\begin{tabular}{ccccc}
\hline Overall Objectives and References to SUP and NBS & Role of SUP & \multicolumn{2}{c}{ Role of NBS } \\
\hline EU Green Public Procurement (GPP), 2014 & R & P & R & P \\
\hline
\end{tabular}

The use of the voluntary EU GPP criteria for public space maintenance has the potential to considerably reduce environmental impacts from public space maintenance and can help stimulate demand for more sustainable goods and services (e.g., eco-innovations and nature-based innovations).

Key GPP criteria:

- $\quad$ Office building design, construction and management Public space maintenance

Road design, construction and maintenance

- Waste-water infrastructure

\section{References}

1. Bader, C.; Bieri, S.; Wiesmann, U.; Heinimann, A. Is Economic Growth Increasing Disparities? A Multidimensional Analysis of Poverty in the Lao PDR between 2003 and 2013. J. Dev. Stud. 2017, 53, 2067-2085. [CrossRef]

2. Millenium Ecosystem Assessent. Ecosystems and Human Well-Being: Synthesis; Millenium Ecosystem Assessent: Washington, DC, USA, 2005; ISBN 9781610914840.

3. Barker, T. Climate Change 2007: An Assessment of the Intergovernmental Panel on Climate Change. Change 2007, 446, 12-17. [CrossRef]

4. Everett, T.; Ishwaran, M.; Ansaloni, G.P.; Rubin, A. Economic Growth and the Environment-Defra Evidence and Analysis Series-Paper 2; MPRA: Munich, Germany, 2010.

5. Crutzen, P.J. Geology of mankind. Nature 2002, 415, 23. [CrossRef]

6. Sterner, T.; Barbier, E.B.; Bateman, I.; van den Bijgaart, I.; Crépin, A.S.; Edenhofer, O.; Fischer, C.; Habla, W.; Hassler, J.; Johansson-Stenman, O. Policy design for the Anthropocene. Nat. Sustain. 2019, 2, 14-21. [CrossRef]

7. Kavalski, E.; Zolkos, M. The recognition of nature in international relations. Recognit. Glob. Polit. Crit. Encount. State World 2016, 139-155. [CrossRef]

8. Wisniewski, R.L. Carrying Capacity: Understanding our Biological Limitations. Humboldt J. Soc. Relat. 1980, 7, 55-70.

9. del Monte-Luna, P.; Brook, B.W.; Zetina-Rejón, M.J.; Cruz-Escalona, V.H. The carrying capacity of ecosystems. Glob. Ecol. Biogeogr. 2004, 13, 485-495. [CrossRef]

10. Alberti, V.; Alonso Raposo, M.; Attardo, C.; Auteri, D.; Ribeiro Barranco, R.; Batista, E.; Silva, F.; Benczur, P.; Bertoldi, P.; Bono, F.; et al. The Future of Cities: Opportunities, Challenges and the Way Forward; Publications Office of the European Union: Luxembourg, 2019; ISBN 9789276038474.

11. Costanza, R.; D’Arge, R.; De Groot, R.; Farber, S.; Grasso, M.; Hannon, B.; Limburg, K.; Naeem, S.; O'neill, R.; Paruelo, J.; et al. The value of the world's ecosystem services and natural capital. Ecol. Econ. 1998, 387, 3-15. [CrossRef]

12. Gascon, M.; Mas, M.T.; Martínez, D.; Dadvand, P.; Forns, J.; Plasència, A.; Nieuwenhuijsen, M.J. Mental health benefits of long-term exposure to residential green and blue spaces: A systematic review. Int. J. Environ. Res. Public Health 2015, 12, 4354-4379. [CrossRef] [PubMed]

13. Gómez-Baggethun, E.; Barton, D.N. Classifying and valuing ecosystem services for urban planning. Ecol. Econ. 2013, 86, 235-245. [CrossRef] 
14. Haase, D.; Larondelle, N.; Andersson, E.; Artmann, M.; Borgström, S.; Breuste, J.; Gomez-Baggethun, E.; Gren, Å.; Hamstead, Z.; Hansen, R.; et al. A quantitative review of urban ecosystem service assessments: Concepts, models, and implementation. Ambio 2014, 43, 413-433. [CrossRef] [PubMed]

15. Ahern, J.; Cilliers, S.; Niemelä, J. The concept of ecosystem services in adaptive urban planning and design: A framework for supporting innovation. Landsc. Urban Plan. 2014, 125, 254-259. [CrossRef]

16. United Nations. New urban agenda-Habitat III. In Proceedings of the United Nations Conference on Housing and Sustainable Urban Development, Quito, Ecuador, 17-20 October 2016; ISBN 9789211327311.

17. ECC. European Economic Community-Traité Instituant La Communauté Économique Européenne. Annu. Eur. Eur. Yearb. 1957, 412-639. [CrossRef]

18. United Nations. United Nations Human Rights Declaration; United Nations: New York, NY, USA, 1948.

19. United Nations. United Nations Conference on the Human Environment [UNCHE]. Stockholm Declaration: A/CONF.48/14/Rev.1. In Proceedings of the United Nations Conference on the Human Environment (Stockholm Conference), Stockholm, Sweden, 5-16 June 1972; EC: Bruxells, Belgium, 1972; p. 77.

20. Holzinger, K.; Sommerer, T. EU Environmental Policy: Greening the World? In EU Policies in a Global Perspective: Shaping or Taking International Regimes? Taylor and Francis: Abingdon, UK, 2014; pp. 111-129. ISBN 9781315867410.

21. Bouwma, I.; Schleyer, C.; Primmer, E.; Winkler, K.J.; Berry, P.; Young, J.; Carmen, E.; Špulerová, J.; Bezák, P.; Preda, E.; et al. Adoption of the ecosystem services concept in EU policies. Ecosyst. Serv. 2017. [CrossRef]

22. Geneletti, D.; Zardo, L. Ecosystem-based adaptation in cities: An analysis of European urban climate adaptation plans. Land Use Policy 2016, 50, 38-47. [CrossRef]

23. Rozas-Vásquez, D.; Fürst, C.; Geneletti, D.; Almendra, O. Integration of ecosystem services in strategic environmental assessment across spatial planning scales. Land Use Policy 2018, 71, 303-310. [CrossRef]

24. EC. Towards an EU Research and Innovation Policy Agenda for Nature-Based Solutions E Re-Naturing Cities: Final Report of the Horizon 2020 Expert Group on 'Nature-Based Solutions and Re-Naturing Cities'; EC: Bruxells, Belgium, 2015; ISBN 9789279460517.

25. EC. Living well, within the limits of our planet. In COM(2012) 710 Final; EC: Bruxells, Belgium, $2012 ;$ p. 37.

26. EEA European Environment Agency. The European Environment-State and Outlook 2020. Knowledge for Transition to a Sustainable Europe; EC: Bruxells, Belgium, 2019; ISBN 9789294800909.

27. CoE. The 8th Environment Action Programme-Turning the trends together. J. Chem. Inf. Model. 2019, $2019,1-10$.

28. EC. The European Green Deal; EC: Bruxells, Belgium, 2019.

29. Claeys, G.; Tagliapietra, S.; Zachmann, G. How to Make the European Green Deal Work; Bruegel Policy Contrib: Bruxells, Belgium, 2019; p. 21.

30. CoE. Council Directive 92/43/EEC of 21 May 1992 on the Conservation of Natural Habitats and of Wild Fauna and Flora; EC: Bruxells, Belgium, 1992; p. 7.

31. de la Fuente, B.; Mateo-Sánchez, M.C.; Rodríguez, G.; Gastón, A.; Pérez de Ayala, R.; Colomina-Pérez, D.; Melero, M.; Saura, S. Natura 2000 sites, public forests and riparian corridors: The connectivity backbone of forest green infrastructure. Land Use Policy 2018, 75, 429-441. [CrossRef]

32. EC. Green Infrastructure (GI)_Enhancing Europe's Natural Capital; EC: Bruxells, Belgium, 2013.

33. EC. EU Biodiversity Strategy for 2030. In COM(2020) 380 Final; EC: Bruxells, Belgium, 2020. [CrossRef]

34. Corlett, R.T.; Primack, R.B.; Devictor, V.; Maas, B.; Goswami, V.R.; Bates, A.; Pin Koh, L.; Regan, T.; Loyola, R.; Pakeman, R.; et al. Editorial-Impacts of the coronavirus pandemic on biodiversity conservation. Biol. Conserv. 2020, 246. [CrossRef]

35. UN. Paris Agreement; EC: Bruxells, Belgium, 2015.

36. EP. Water Framework Directive 2000/60/EC. Directive 2000/60/EC of the European Parliament and of the Council of 23 October 2000 Establishing a Framework for Community Action in the Field of Water Policy; EC: Bruxells, Belgium, 2000.

37. EP. Directive 2007/60/EC of the European Parliament and of the Council of 23 October 2007 on the Assessment and Management of Flood Risks; EC: Bruxells, Belgium, 2007.

38. Naumann, S.; Davis, M. Sustainable Use of Land and Nature-Based Solutions Partnership Better Regulation to Boost NBS at European, National and Local Level; EC: Bruxells, Belgium, 2020.

39. EUROSTAT. Eurostat Regional Yearbook 2017; EC: Bruxells, Belgium, 2017.

40. Jongman, B.; Ward, P.J.; Aerts, J.C.J.H. Global exposure to river and coastal flooding: Long term trends and changes. Glob. Environ. Chang. 2012, 22, 823-835. [CrossRef]

41. Bukvic, A.; Rohat, G.; Apotsos, A.; de Sherbinin, A. A systematic review of coastal vulnerability mapping. Sustainability 2020, 12, 2822. [CrossRef]

42. Forzieri, G.; Feyen, L.; Russo, S.; Vousdoukas, M.; Alfieri, L.; Outten, S.; Migliavacca, M.; Bianchi, A.; Rojas, R.; Cid, A. Multi-hazard assessment in Europe under climate change. Clim. Chang. 2016, 137, 105-119. [CrossRef]

43. Athanasiou, P.; van Dongeren, A.; Giardino, A.; Vousdoukas, M.I.; Ranasinghe, R.; Kwadijk, J. Uncertainties in projections of sandy beach erosion due to sea level rise: An analysis at the European scale. Sci. Rep. 2020, 10, 1-14. [CrossRef]

44. Bosello, F.; Nicholls, R.J.; Richards, J.; Roson, R.; Tol, R.S.J. Economic impacts of climate change in Europe: Sea-level rise. Clim. Change 2012, 112, 63-81. [CrossRef]

45. Gracia, A.; Rangel-Buitrago, N.; Oakley, J.A.; Williams, A.T. Use of ecosystems in coastal erosion management. Ocean. Coast. Manag. 2018, 156, 277-289. [CrossRef] 
46. Narayan, S.; Beck, M.W.; Reguero, B.G.; Losada, I.J.; Van Wesenbeeck, B.; Pontee, N.; Sanchirico, J.N.; Ingram, J.C.; Lange, G.M.; Burks-Copes, K.A. The effectiveness, costs and coastal protection benefits of natural and nature-based defences. PLoS ONE 2016. [CrossRef] [PubMed]

47. EP. Directive 2008/56/EC of the European Parliament and of the Council of 17 June 2008 Establishing a Framework for Community Action in the Field of Marine Environmental Policy (Marine Strategy Framework Directive); EC: Bruxells, Belgium, 2008.

48. EC. Proposal for a Directive of the European Parliament and of the Council Establishing a Framework for Maritime Spatial Planning and Integrated Coastal Management; EC: Bruxells, Belgium, 2013.

49. EC. White Paper Adapting to Climate Change: Towards a European Framework for Action; EC: Bruxells, Belgium, 2009.

50. EC. Commission Staff Working Document Guidelines on Developing Adaptation Strategies; EC: Bruxells, Belgium, 2013.

51. Mysiak, J.; Castellari, S.; Kurnik, B.; Swart, R.; Pringle, P.; Schwarze, R.; Wolters, H.; Jeuken, A.; Van Der Linden, P. Brief communication: Strengthening coherence between climate change adaptation and disaster risk reduction. Nat. Hazards Earth Syst. Sci. 2018, 18, 3137-3143. [CrossRef]

52. EC. Forging a Climate-Resilient Europe-The New EU Strategy on Adaptation to Climate Change; EC: Bruxells, Belgium, 2021.

53. EC. Stepping up Europe's 2030 Climate Ambition. Investing in a Climate-Neutral Future for the Benefit of Our People; EC: Bruxells, Belgium, 2020.

54. Ghisellini, P.; Cialani, C.; Ulgiati, S. A review on circular economy: The expected transition to a balanced interplay of environmental and economic systems. J. Clean. Prod. 2016, 114, 11-32. [CrossRef]

55. Parnell, S. Defining a Global Urban Development Agenda. World Dev. 2016, 78, 529-540. [CrossRef]

56. Prendeville, S.; Cherim, E.; Bocken, N. Circular Cities: Mapping Six Cities in Transition. Environ. Innov. Soc. Transit. 2018, 26, 171-194. [CrossRef]

57. EC. Communication from the Commission-Towards a Circular Economy: A Zero Waste Programme for Europe; EC: Bruxells, Belgium, 2014.

58. Urban Agenda for the EU; EC: Bruxells, Belgium, 2016.

59. EC. A New Circular Economy Action Plan For a Cleaner and More Competitive Europe EN; EC: Bruxells, Belgium, 2020.

60. Urban Agenda Partnership Sustainable and Circular Re-Use of Spaces E Buildings HANDBOOK; EC: Bruxells, Belgium, 2019.

61. Noble, B.; Nwanekezie, K. Conceptualizing strategic environmental assessment: Principles, approaches and research directions. Environ. Impact Assess. Rev. 2017, 62, 165-173. [CrossRef]

62. EP. Directive 2001/42/EC of the European Parliament and of the Council of 27 June 2001 on the Assessment of the Effects of Certain Plans and Programmes on the Environment; EC: Bruxells, Belgium, 2001; p. 30. [CrossRef]

63. Vargas, A. Including Land Take and Soil Properties in Impact Assessment Procedures; EC: Bruxells, Belgium, 2019; pp. 1-44.

64. Mačiulytė, E.; Durieux, E. Public Procurement of Nature-Based Solutions. Addressing Barriers to the Procurement of Urban NB: Case Studies and Recommendations; EC: Bruxells, Belgium, 2020; ISBN 9789276216018. 